\title{
A CASE OF SUBMUCOUS LIPOMA OF THE PELVIC COLON
}

\author{
By A. M. B. Tompkin, M.B., F.R.C.S. \\ Resident Assistant Surgeon, West London Hospital
}

On survey of the available literature it appears that lipomata form an uncommon group of benign tumours occurring in the alimentary system, and are usually found at post-mortem examination. Pre-operative diagnosis with subsequent operative and pathological confirmation is distinctly rare.

There appears to be little agreement in the distribution of lipomata throughout the various parts of the alimentary tract, but what does seem evident is that only a very small proportion of lipomata fall into the category of 'symptom producing' tumours. Intussusception is probably the commonest presenting condition, and Comfort found that it occurred 26 times as a complication in 29 cases of lipoma of the small bowel, and 33 times in 62 cases in the large bowel.

The most important differential diagnosis when considering the colonic lipomata is of course carcinoma, and the relative frequency and importance of this condition overshadows all benign lesions.

If the case presents as one of complete intestinal occlusion it would perhaps be possible to distinguish the two conditions by emergency barium enema examination. In the incompletely occluded case, signs of intermittent obstruction due to subacute intussusception may be the presenting condition, as in the case described below, but here the differential diagnosis depends wholly on the radiological appearance with opaque enema, the filling defect in the lumen of the bowel in the benign case being smooth in outline, whereas in the malignant case the filling defect shows varying degrees of irregularity with destruction of the mucosal pattern.

I consider the case detailed below worthy of record on three accounts; first, it did not, as has so frequently occurred in recorded cases, present as an abdominal emergency; secondly, 'benign neoplasm of the pelvic colon' was reported while the patient was still under investigation as an outpatient; and finally, armed with this knowledge successful limited resection was carried out without concern for the distant lymphatic field.

\section{Case Report}

J. H. aged 52 , a clerk, attended the out-patient department of the West London Hospital on March 30, 1954, complaining of lower left-sided $\omega$ abdominal pain and bloody diarrhoea. His symp- $\infty$ toms had been present for one week, and he attributed them to a dose of Epsom salts he had $\vec{\circ}$ taken prior to the 'attack.' On the day of his 0 attendance he had passed a normal stool.

\section{History}

Apart from bilateral apical tuberculosis discovered by mass radiography in 1946, the only point of interest in his past history was that he hag attended the out-patient department of the Wes London Hospital in May 1952 complaining right-sided abdominal pain, which he stated had been present off and on for three years. A followthrough barium meal of the ileo-caecal region $\overline{0}$ showed a non-filling appendix with some localized tenderness. It is noteworthy that the radiologist $\stackrel{\square}{\circledR}$ reported that there was in addition tenderness over $\overrightarrow{\vec{B}}$ the middle of the descending colon. Following $\frac{9}{3}$ the opaque meal, interval appendicectomy was $\supset$ carried out through a gridiron incision. The appendix removed showed no macroscopic evi- $\overline{0}$ dence of abnormality. He made a good recovery 3 from this operation and was symptom free when followed up in the out-patient department. $\mathrm{He}$ did not attend hospital again between July 1953 and March 1954. In retrospect, it would seem reasonable to attribute the right iliac fossa pain $\bigcirc$ present three years before appendicectomy, to $D$ caecal distension from intermittent partial occlusion of the pelvic colon.

On examination the patient appeared to be in good health, but somewhat thin. Abdominal examination, including auscultation, showed no abnormality. Digital examination of the rectum and proctoscopy were likewise negative. Sigmoidoscopy to seven inches in out-patient department revealed no abnormality apart from a gross excess of clear mucus from the bowel above. 


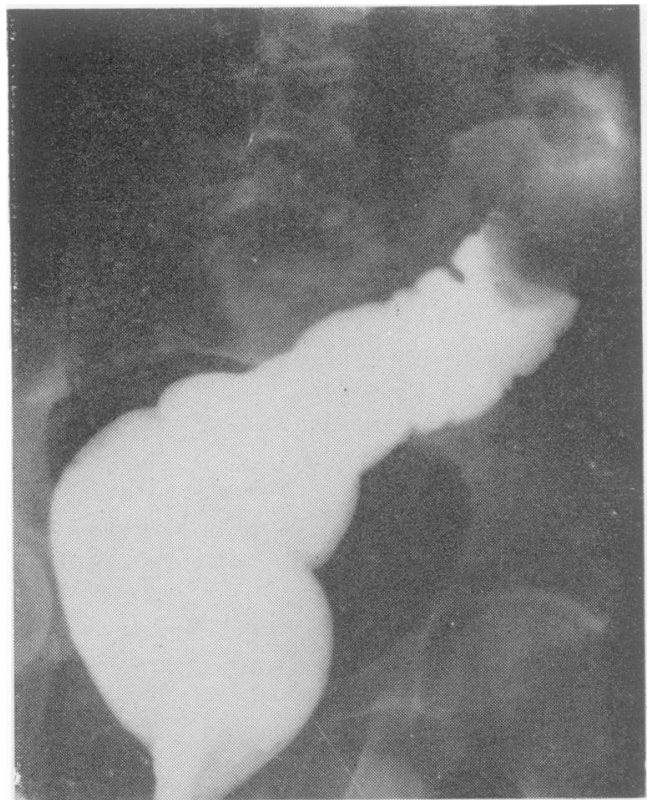

FIG. r.-Arrested flow of barium in pelvic colon.

\section{Investigations}

Barium enema examination showed the passage of the opaque fluid to be obstructed in the region of the pelvic colon and an appearance resembling those of an intussusception (Fig. I). With coaxing and considerable discomfort to the patient the barium passed to the caecum. A large filling defect with a smooth spherical outline was present in the pelvic colon, the appearance being shown very clearly in the after evacuation film. A diagnosis of benign neoplasm of the pelvic colon was made.

Haemoglobin: 95 per cent.

Red blood cells: $4,840,000$ per cu. $\mathrm{mm}$.
White blood cells: 7,600 per cu. mm. Erythrocyte sedimentation rate: $6 \mathrm{~mm}$.

Wassermann and Kahn reactions: negative.

Blood urea: $32 \mathrm{mg}$. per cent.

$X$-ray of chest: healed bilateral apical lesions of old tuberculous infection.

\section{Operation}

The abdomen was explored through a lower left paramedian incision, May 6, 1954. The pelvic colon was seen to contain a solid mass $I \frac{1}{2}$ in. in all diameters, freely mobile within the lumen of the bowel. There was no evidence of intussusception and no mesenteric glands were palpable. The operative findings again supported the radiological appearance of a benign lesion, and therefore limited resection of the colon was carried out. It was noted that the proximal bowel was generally thickened for a distance of 5-6 in. above the tumour, compared with the bowel wall below the lesion. End to end anastomosis was carried out using one layer of interrupted thread sutures. (No. 50).

\section{Specimen-(see Fig. 2)}

A pedunculated ovoid tumour, $1 \frac{3}{4}$ in. in its main diameter, was seen to occupy the lumen of the bowel, the proximal portion of the latter showing hypertropic changes. On cut section the tumour was seen to be composed of a fatty mass covered by normal mucous membrane, except for some slight ulceration about the proximal end. The specimen showed the microscopical appearances of a submucous lipoma, the muscularis mucosae passing over the surface of the tumour, except of course, in the area showing ulceration.

\section{Progress}

Post-operatively the patient made an uneventful recovery, a spontaneous action of the bowels

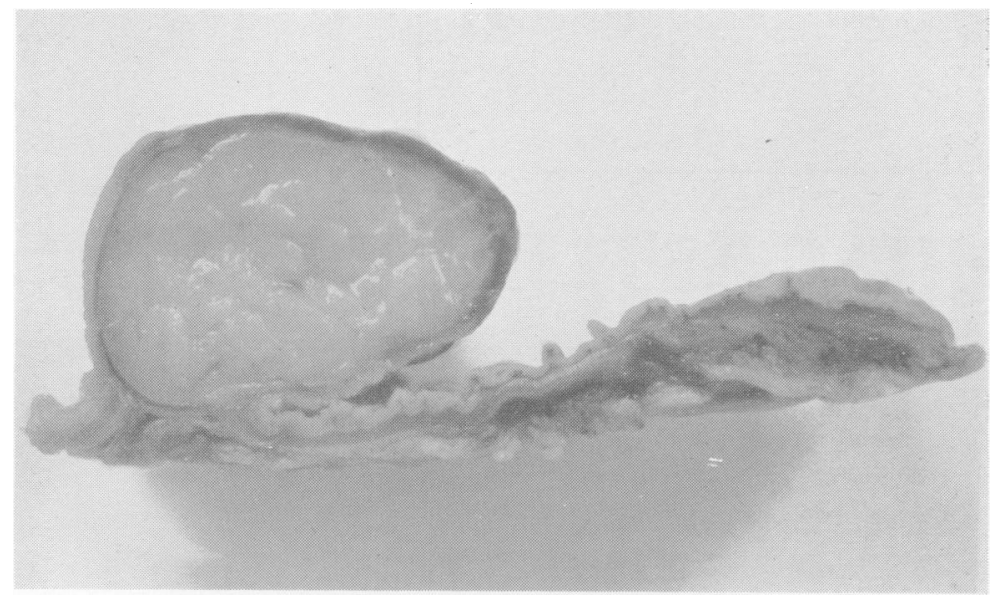

FIG. 2.-Macroscopical appearance of cut surface of tumour. 
occurring on the fifth post-operative day. He has been followed up now for about eighteen months and has remained, as expected, in excellent health.

\section{Literature}

The first case of submucous lipoma of the gastrointestinal tract was reported in 1835 by Cruveilhiers, this being a sessile lipoma situated near the pylorus. Stetton (I 909) states that these tumours occur with equal frequency in the large and small bowel, and also that there is an equal sex incidence. Virchow, however, states that lipomata are more common in the stomach and upper parts of the small intestine. Brunner (1897) discovered a lipoma on rectal examination, and Mattes (r909) described a case in a 76 year old male, in which a tumour $4 \times 6 \mathrm{~cm}$. repeatedly appeared at the anus after replacement. Between I835 and I93I, I8I cases are known to have occurred, these taking into account all sites in the gastro-intestinal tract. Staemmler (1924) records i 6 cases of adenomatous polypi of the large and small gut and only nine lipomata and nine myomata in 1,700 postmortem examinations. Staemmler also states that lipomata are half again as common in the large bowel as in the small intestine, and those producing symptoms twice as common in the large gut as compared with the small. Comfort (I93I) reported 28 cases of submucous lipomata of the gastro-intestinal tract, only three of which produced symptoms. One of this series was seen at operation and the other 27 cases were found in the course of 3,924 autopsies. In his paper Comfort points out that a very high proportion of cases occur after the age of 39 years, and in reviewing the recorded cases up till I $93 \mathrm{I}$, notes that 23 lipomata have been felt on abdominal examination and that spontaneous expulsion from the bowel has occurred 12 times, but only twice since 1909 .

\section{Presentation and Diagnosis}

Intussusception is probably the commonest $\frac{2}{\mathrm{D}}$ presenting condition, and Comfort found that it $\stackrel{\varrho}{c}$ occurred 26 times as a complication of 29 cases of lipoma of the small bowel, and 33 times in $62 \stackrel{\vec{S}}{\rightarrow}$ cases in the large bowel. When considering the subject it is of course obvious that the exact histological nature of the benign tumour cannot be $\frac{\bar{\rho}}{\vec{D}}$ ascertained in life without a biopsy. Theoretically, $\stackrel{\varnothing}{\varnothing}$ this could be obtained if the mass prolapsed at the anus was low enough in the rectum to be delivered $s$ through the sphincter, or formed the apex of an intussusception. Even in these circumstances $\overrightarrow{\vec{\omega}}$ biopsy would hardly be a practical proposition in $\mathscr{\sigma}^{\circ}$ association with intussusception. Again, in retro- $\overrightarrow{8}$ spect, it should be a practical proposition to per- 3 . form enterotomy and remove the lipoma by submucous enucleation, although I can find no $\omega$ reference to this having been attempted.

\section{Acknowledgments}

Grateful acknowledgment is made to Mr. G. F. 옥 Grant Batchelor for allowing me to publish the $\vec{c}$ paper, and I would like to thank Dr. H. W. A. Post $\frac{\mathbb{D}}{8}$ and Dr. R. Waller for their help concerning the radiology and pathology respectively.

\section{BILBIOGRAPHY}

BRUNNER, C. (1899), Beitr. F. Rhin. Chir., xxv, 344-363. COMFORT, M. W. (г931), Surg. Gynec. Obstet., lii, rог. CRUVEILHIERS, J. B. (1835), 'Maladies de l'estomac. Atlas d'anatomie pathologique du corps,' Paris, vol. II, p. 3 .

MATTES, F. (1909), 'Ueber darminvagination infolge von darmtumcren nebst einem kasuistischen beitrag aus der, chirurgisslıen. Universitaet Shlinlk zu Freiburg im Breisgan,' Freiburg in Baden, p. 92.

STAEMMLER, M. (1925), ' Das Lipom in, Reichel und Staemmler, die Neubildungen des Darmes,' Stuttgart Enke, part I, pp. 273-279.

STETTON, D. (1909), Surg. Gynec. Obstet., i, 1 56-1 76.

\section{RUTHIN CASTLE, NORTH WALES}

A Clinic for the diagnosis and treatment of Internai Discases (except Mental or Infectious Diseases). The Clinic is provided with a staff of doctors, technicians and nurses.

The surroundings are beautiful. The climate is mild. There is central heating throughout. The annual rainfall is 30.5 inches, that is, less than the average for England.

The Fees are inclusive and vary according to the room occupied.

For particulars apply to THE SECRETARY, Ruthin Castle, North Wales.

Telegrams: Castle, Ruthin

Telephone: Ruthin 66 